\title{
How we do it: endoscopic trans-nasal repair of CSF rhinorrhoea Ifran Syed ${ }^{* 1}$, Tahwinder Upile ${ }^{2}$ and Simon Hickey ${ }^{1}$
}

Address: ${ }^{1}$ Department of Head \& Neck Surgery, Torbay General Hospital, Torquay, UK and ${ }^{2}$ UCL Ear Institute \& Department of Surgery, University College London, London, UK

* Corresponding author

from Ist Scientific Meeting of the Head and Neck Optical Diagnostics Society

London, UK. 14 March 2009

Published: 28 July 2009

Head \& Neck Oncology 2009, I(Suppl I):P3 I doi:I0.I |86/I758-3284-I-SI-P3 |

This abstract is available from: http://www.headandneckoncology.org/content/I/SI/P3 I

(C) 2009 Syed et al; licensee BioMed Central Ltd.

Endoscopic repair of CSF rhinorrhoea was first described in the early 1980s. Since then the endoscopic approach has overtaken the intracranial route as the procedure of choice due to superior visualisation of the operative field, reduced operating time \& lower complication rates. Various autogenous, allogenic and synthetic patching materials have been used to augment repair. We describe a step wise technique of patching the skull base defect using a combination of septal mucoperichondrial flap and tensor fascia lata graft. 